ఠ RAPID COMMUNICATION

\title{
From P0 to P6 medicine, a model of highly participatory, narrative, interactive, and "augmented" medicine: some considerations on Salvatore laconesi's clinical story
}

\author{
This article was published in the following Dove Press journal: \\ Patient Preference and Adherence \\ 23 April 2013 \\ Number of times this article has been viewed
}

\author{
Nicola Luigi Bragazzi \\ School of Public Health, Department \\ of Health Sciences (DISSAL), Genoa, \\ Italy
}

\begin{abstract}
Salvatore Iaconesi was recently diagnosed with a brain tumor. He decided to share his clinical records not only with doctors but with everybody who wishes to find him a cure. "Because cure is not unique," he emphasizes "there are cures for the body and cures for the soul, and everyone, from a painter to a musician, can find me a cure. Please, feel free to take my clinical history for example and let it become a game, a video, a music, a picture, whatever you like." The emblematic hallmark of the changing times, Salvatore Iaconesi's case is an example of how many profound revolutions and steps medicine has undertaken during the past few centuries. Stemming from a form of remote medical paternalism and arriving at the concept of a therapeutic alliance, medicine nowadays faces challenges and opportunities at a level before unforeseeable and unimaginable. The new concept of P6 medicine (personalized, predictive, preventive, participatory, psychocognitive, and public) is discussed, together with its profound implications.
\end{abstract}

Keywords: cancer, narrative medicine, paternalistic medicine, P4 medicine, P5 medicine

\section{Introduction}

Medicine has undergone many changes and has faced different challenges during the course of its history, some of them motivated by advancements and developments brought along by new technologies (such as the introduction of powerful medical imaging devices) but passively felt by the patients, others instead proactively fostered by patients themselves. Some examples of these are the creation and the development of patient peer-to-peer communities and other kinds of support groups, or a more autonomous patient entrepreneurship in health-seeking behaviors and self-care practices.

Involving patients in the health care process is an added value, as patients have a unique knowledge of their own health status: ${ }^{1}$ this is the so-called theory of the "expert patient," that is to say a model of a patient that knows himself/herself better than a physician could, and one who has a tacit and implicit knowledge of his/her disease could more properly interact with the physician and take part in each step of the therapeutic process. ${ }^{2,3}$ In fact, shared medical decisions have been proven to result in better therapeutic compliance and clinical outcomes. ${ }^{2-4}$

Patients' participation has been increasing over the last several years, but still some barriers remain: ${ }^{5,6}$ patients should be more involved in service planning and evaluation (while sometimes this is just limited to completing satisfaction surveys), in making services more accessible and information delivery more understandable, reducing medical errors
Correspondence: Nicola Luigi Bragazzi School of Public Health, Department of Health Sciences (DISSAL), Via Antonio Pastore I, 16132, Genoa, Italy

Tel +390103537664

Fax +390103537669

Email 3762387@studenti.unige.it; robertobragazzi@gmail.com 
and improving a patient's safety, ${ }^{7}$ as well as advocating and promoting more medical coordination, given that health care is multidisciplinary and complex nowadays. However, mere consultation is often mistaken for negotiating and interactive partnership, and thus the patient still holds a passive role. ${ }^{8}$

Even though practitioners and professionals are of vital importance in enhancing the patients' participation, and since this is universally acknowledged as a crucial strategy, ${ }^{9}$ unfortunately many doctors and health managers seem unwilling to involve patients in the health care process; ${ }^{10,11}$ this is often due to organizational and institutional difficulties, ${ }^{12}$ restraint of time and resources, and a lack of motivation and interest.

Another reason for this barrier may be that there are very few academic courses in the medical syllabus focusing on this integrated and highly stratified approach, and thus practitioners are not adequately trained or sufficiently educated.

Involving patients is particularly important in cancer networks; cancer is a disease of high psychological burden and impact. The social, cultural, spiritual, and religious needs of the patients should be considered by the physician while choosing the treatment. ${ }^{13}$ Oncologists are usually challenged by the disclosure of a cancer diagnosis, fearing that this would have a negative impact on the therapeutic process, causing distress, pain, suffering, and hopelessness in the patient. Moreover, they are afraid of harming the patients, even if surveys have shown that patients would prefer to be informed of their disease. ${ }^{14}$

Greater difficulties are encountered when communicating a cancer diagnosis to adolescents and young adults (AYA, or individuals between 15 and 39 years) for several reasons, including the fact that physicians have to mediate between the adolescent's need for independence and self-sufficiency and the parents' requests and demands. Moreover, because of the nature of this critical developmental transition phase, cancer may undermine AYA's self-identities as well their social relationships, in which sexual maturation, intimacy, and peer networks and influences play a major role. ${ }^{15}$ AYA's psychological adjustment and coping skills are still immature, and special features characterize the prognosis of cancer in young adults, such as the rarity of the oncotype, which can yield poorer outcomes and require a particularly prolonged and demanding therapy which can jeopardize the young patient's adherence and compliance. ${ }^{16}$ On the other hand, a very low rate of AYA participate in clinical trials and only a small percentage (between $27 \%$ and $60 \%$ ) is compliant to the therapeutics. ${ }^{16}$ Yet the Internet and other forms of communication and participation could enhance AYA's adherence and health outcomes. ${ }^{17}$ A new model of participatory, highly interactive, narrative and "augmented" medicine could be particularly appropriate for them. ${ }^{18}$
Here, inspired by the recent true clinical story of a patient, we make an overview of some fundamental steps and revolutionary models of medicine, and we will discuss their consequences and impact on routine clinical practice.

\section{Salvatore laconesi's clinical case}

Salvatore Iaconesi is a talented computer scientist and a skilled and polyvalent artist who was abruptly diagnosed with a brain tumor, and from one day to another he found himself experiencing the tragic odyssey of cancer. ${ }^{16}$ Since "my tumor is also an opportunity" (as other oncology patients have said in their narrative stories), ${ }^{17,20}$ and since computers and art are all integral to his life, he surprisingly decided to share his medical records with everybody on his website. ${ }^{21}$ However, his clinical records were in a proprietary format file, so he had to crack them as a hacker. Like an open-source software that is easily available on the public domain, users can freely download, edit, or reuse these records; he thus wanted to make his cure an "open-source cure." Not only doctors, but literally everybody, can consult his data, grab information on his disease, share his pain, and even find him a cure.

Because cure is not unique - he emphasizes - its meaning varies according to the cultures and the traditions. There are cures for the body and cures for the soul, and everyone, from a painter to a musician, can find me a cure. Please, feel free to take my clinical story for example and let it become a game, a video, a music, a picture ... whatever you like. ${ }^{21}$

His disease has thus become globally shared, has hybridized all boundaries, connected science and humanities, and made science a little more human and familiar. His disease has pervaded any aspect of real life, it now has a face, and it is not only a mere nosological classification on medical textbooks.

The impact that Salvatore is having on public opinion is tremendous: in a few days, up to 300 people have replied to his blog's request, with lay people compromising the majority (70\%), while the remainder are doctors. ${ }^{21,22}$ Even politicians have shown interest and have proposed a point of order in the Italian Parliament in order to promote the development and the spreading of clinical records in an open format file.

Emblematic hallmark of the changing times, Salvatore Iaconesi's case illustrates how many profound revolutions and steps medicine has undertaken during the centuries. Stemming from a form of remote medical paternalism and arriving at the concept of a therapeutic alliance, medicine is now faced with challenges and opportunities at a level before unforeseeable and unimaginable. 
Once upon a time there was P0 medicine; now is the era of P6 medicine.

\section{From P0 to P5 medicine}

P0 medicine is the dawn of medicine, characterized by paternalism and little, if any, autonomy of the patient. ${ }^{23,24}$ Physicians tended to hide and conceal diagnoses to the patients, use reassuring and allusive terms, and did not consult the patients, believing that patients need to be protected from despair and guided through their diagnoses as if physicians are in charge of them. Paternalism can be defined in different ways according to the different degrees of freedom and autonomy that doctor concedes to the patient (paternalistic model, autocratic model, agent model, yielding autonomy model), but despite this, P0 remains deeply physician-centered.

Gradually we passed from P0 medicine to P3 and P4 medicine, models which were both proposed by Leroy Hood, a molecular biologist and oncologist, and defined as participatory, personalized, predictive, and preventive (the term "participatory" was not included in the initial P3 model formulation). ${ }^{25}$

This transition may be due, as suggested by some scholars, to the change in the process of making the diagnosis itself: while earlier there were only the physician, the patient, and the disease (that is to say, a tripartite model), and there was little technology. Nowadays the involvement of technology in medicine has increased exponentially to an unprecedented level.

Diagnosis has become extremely complex and interdisciplinary, and this has partially challenged the paternalistic model.

P5 medicine is the next step, recently proposed by Gorini and Pravettoni, ${ }^{26,27}$ as well as by Ozdemir et al, ${ }^{28}$ with the fifth "P" representing psychocognitive, a fundamental aspect of the model that has been ignored for so much time.

\section{Why participatory medicine?}

P5 medicine is patient-centered, ${ }^{29,30}$ the patient is constantly kept informed of every aspect of his/her disease, and his/ her quality of life is not just an accessory element in decision making, but it becomes an integrated parameter in the delivery of the cure.

Moreover, the patient is gradually becoming self-aware of his/her lifestyle, understanding how his/her own decisions can have an influence on his/her health state.

However, informing patients about the risks and benefits of alternative treatment options and choosing between them is becoming a bigger challenge as knowledge about the relationship between the individual's molecular profile and the effectiveness of available medications grows. ${ }^{31,32 ~ " F a c t s ~}$ are uncertain, values in dispute, stakes high and decisions urgent and where no single one of these dimensions can be managed in isolation from the rest." ${ }^{\prime 33}$ For these reasons, communicating and sharing the risks and uncertainties have a profound ethical value. ${ }^{34,35}$

Participatory medicine makes efforts to ensure equity in health care access by designing, developing, and implementing health policies, in which stakeholders and laymen are deeply involved.

\section{Why personalized medicine?}

Curiously, "personalized medicine"36,37 was a concept prompted by geneticists as a natural advancement in cellular and molecular biology. It is personalized in the sense that thanks to a unique combination of high-throughput technologies, both labeled and label-free, and of both nanogenomics and nanoproteomics, ${ }^{38-44}$ it is possible to tailor specific therapeutics to the specific molecular picture of the patient. ${ }^{45}$

In this way, treatments would be more effective and would be associated with a lower percentage of adverse drug reactions.

Traditionally, diseases have been considered as a cluster of symptoms (syndromes), and differential diagnosis has been the gold standard of making a diagnosis. However, many diseases are multifaceted, and there are multifactorial pathologies; therefore, a classical method has proven to be too simple to capture this complexity.

On the other hand, molecular classification has been well known in helping and improving clinical nosological taxonomy. Under the same umbrella, different diseases with different prognoses can coexist (eg, breast cancer). This approach can definitely improve the outcome of patient management and care. Moreover, this aspect of integrated molecular and biological assessment is to be stressed within the frame of tailored and targeted therapeutics, which recently emerged as promising and exciting trends. Disease is thus shifting from an atheoretical, context-free, "platonic" onesize-fits-all model to an approach that really focuses on each patient's characteristics and needs.

The most important application of personalized medicine is "network medicine," an approach recently proposed by Barabási. ${ }^{46-48}$

Personalized thus refers to the biochemical and biophysical pathways that are up-regulated or down-regulated 
in a patient, but it does not refer to a patient's more ontological, philosophical, and psychological properties, those properties that make the patient a "person" (from Latin "persona").

\section{Why predictive medicine?}

The main aims of predictive medicine are to try to predict disease occurrence or the development of further diseases and complications in an already ill subject.

Predictive medicine is evidence-based medicine, ${ }^{49}$ and refers to the use of models and equations to predict a patient's future health status in order to adopt the best strategy available. An integrative personal omics profile analysis is perhaps the most astonishing application of predictive medicine or "precision medicine" (as it is sometimes termed), connecting multiple high-throughput based data at different levels (genomics, proteomics, and other dynamic omics sources). In this way, it was able to predict the onset of diabetes some months in advance. ${ }^{50}$

Once again, we underline the importance of not separating predictive medicine from patient-centered medicine. ${ }^{51}$

\section{Why preventive medicine?}

Knowing the molecular picture of the patient and considering the disease as a whole using a systematic approach, as well as taking into account environmental factors and psychological profile (the so-called Hippocrates' triad, which represents a sophisticated evolution of the previous Hippocratic dyad), doctors should be able to advise patients as to the right therapeutics for preventing particular diseases. Moreover, new assessment tools enable early diagnosis of diseases, and thus medicine has shifted from being just reactive to being proactive. $^{52}$
Physicians should focus more on health than on disease, and shift from an illness-centered approach to a holistic one. New risk factors are being discovered, and new tools for patient assessment and stratification are being implemented. Molecular signatures and biomarkers enable doctors to monitor patients' health status throughout time in a noninvasive way.

\section{Why psycho-cognitive medicine?}

Nowadays, psychological health is considered to be a fundamental aspect of patients' well-being, and psychology plays different roles in medicine, ranging from treatment compliance and adherence, to gaining access to the treatment itself (traditional versus alternative or complementary therapies), and to creating therapeutic alliances in a broad sense.

Health has been defined by the World Health Organization as a state of complete physical, mental, and social wellbeing, emphasizing the shift from the dominant paradigm of disease to the new paradigm of wellness as a whole..$^{53}$

In order to overcome a reductionist approach, a biopsychosocial model was proposed by Engel. ${ }^{54,55}$

Psychological and personal variables influence the clinical outcome in terms of quality of life, helping to preserve the patient's vitality and satisfaction.

Patients' reactions to communicating about their disease (emotions, feelings like despair and hope, as well as beliefs and behaviors) are fundamental parameters.

A key role in psycho-cognitive medicine is undoubtedly played by health education.

\section{From P5 to P6 medicine: Salvatore laconesi's clinical history}

What we call P6 medicine was termed as "P4 $+\mathrm{C}^{\mathrm{n}}$ Hippocratic revolution" by Cumming et al, ${ }^{56}$ where $\mathrm{C}^{\mathrm{n}}$ stands

Table I The different models of medicine throughout the decades

\begin{tabular}{|c|c|c|c|c|}
\hline PO medicine & P3 medicine & P4 medicine & P5 medicine & P6 medicine \\
\hline $\begin{array}{l}\text { Nonpersonalized, or } \\
\text { one-size-fits-all }\end{array}$ & Personalized & Personalized & Personalized & Personalized \\
\hline Nonpredictive & Predictive & Predictive & Predictive & Predictive \\
\hline $\begin{array}{l}\text { Nonpreventive; addresses } \\
\text { acute diseases. It is a "reactive" } \\
\text { kind of medicine }\end{array}$ & $\begin{array}{l}\text { Preventive; addresses } \\
\text { both acute and chronic } \\
\text { multifactorial diseases. } \\
\text { It is "proactive" }\end{array}$ & $\begin{array}{l}\text { Preventive; addresses } \\
\text { both acute and chronic } \\
\text { multifactorial diseases. } \\
\text { It is "proactive" }\end{array}$ & $\begin{array}{l}\text { Preventive; addresses } \\
\text { both acute and chronic } \\
\text { multifactorial diseases. } \\
\text { It is "proactive" }\end{array}$ & $\begin{array}{l}\text { Preventive; addresses } \\
\text { both acute and chronic } \\
\text { multifactorial diseases. } \\
\text { It is "proactive" }\end{array}$ \\
\hline $\begin{array}{l}\text { Nonparticipatory, rather } \\
\text { paternalistic, or physician- } \\
\text { centered. }\end{array}$ & $\begin{array}{l}\text { Nonparticipatory, rather } \\
\text { paternalistic, or physician- } \\
\text { centered }\end{array}$ & $\begin{array}{l}\text { Participatory, or patient- } \\
\text { centered }\end{array}$ & $\begin{array}{l}\text { Participatory, or patient- } \\
\text { centered }\end{array}$ & $\begin{array}{l}\text { Participatory, or patient- } \\
\text { centered }\end{array}$ \\
\hline Nonpsycho-cognitive & Nonpsycho-cognitive & Nonpsycho-cognitive & Psycho-cognitive & Psycho-cognitive \\
\hline Nonpublic & Nonpublic & Nonpublic & Nonpublic & $\begin{array}{l}\text { Public and population-based; } \\
\text { shared and open-source }\end{array}$ \\
\hline
\end{tabular}




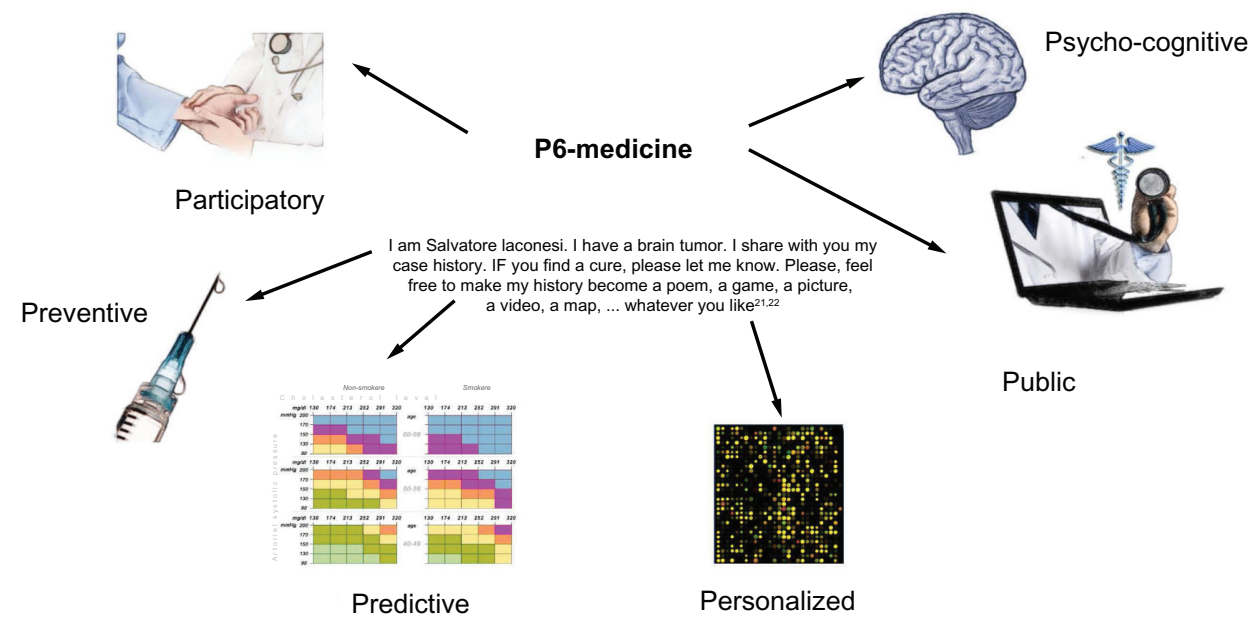

Figure I A pictorial scheme of the elements that comprise P6 medicine, namely “personalized," “preventive," “participatory,” “predictive,” “psychocognitive,” and "public.”2

for "community, collaboration, self caring, co-creation, coproduction, and co-development using technologies delivered via the internet." The novelty of P6 medicine in respect to P5 medicine is the "Health Web Science," a unique combination of e-health, e-medicine, and telemedicine, in which computers and innovative online health communities play a central role. Patients do not limit themselves to browse healthrelated information on the Web, but they actively exploit all of the Web's potential. ${ }^{57,58}$ In this sense, P6 medicine incorporates P5 medicine, because once again the patient is clearly at the center of the medical services.

\section{P6 medicine has profound clinical, ethical, and legal implications}

Salvatore Iaconesi's history can be understood only in the frame of P6 medicine, a new health scenario whose evolution is briefly summarized in Table 1 and in Figure 1. The extremely courageous action of Salvatore Iaconesi to make his clinical records and his story available on the public domain has a deep impact on routine clinical practice and bioethics. Salvatore Iaconesi wanted to challenge the taboos about cancer and to break down the wall of silence. On the one hand, concepts such as individual responsibility, patient choices and preferences, as well as a different patientphysician relationship are strongly advocated and stressed. On the other hand, we are forced to rethink consolidated concepts like privacy and official documents, which represent the very heart of ethics itself. If Iaconesi advocates for a more open, public form of medicine, its limitations and barriers are to be taken into consideration in order to exploit and benefit from the enormous potentials of P6 medicine.

\section{Acknowledgment}

The author thanks webdesigner Assia Franceschini for help in the preparation of Figure 1.

\section{Disclosure}

The author reports no conflicts of interest in this work.

\section{References}

1. Say RE, Thomson R. The importance of patient preferences in treatment decisions-challenges for doctors. BMJ. 2003;327(7414):542-545.

2. Granatir T. The expert patient. Health Serv J. 2008;Suppl:26-27.

3. Abraham C, Gardner B. What psychological and behaviour changes are initiated by 'expert patient' training and what training techniques are most helpful? Psychol Health. 2009;24(10):1153-1165.

4. Hibbard JH. Engaging health care consumers to improve the quality of care. Med Care. 2003;4(Suppl 1):I61-I70.

5. Crawford MJ, Rutter D, Manley C, et al. Systematic review of involving patients in the planning and development of health care. BMJ. 2002; 325(7375): 1263

6. Charles C, Gafni A, Whelan T. Decision-making in the physician-patient encounter: revisiting the shared treatment decision-making model. Soc Sci Med. 1999;49(5):651-661.

7. Longtin Y, Sax H, Leape LL, Sheridan SE, Donaldson L, Pittet D. Patient participation: current knowledge and applicability to patient safety. Mayo Clin Proc. 2010;85(1):53-62.

8. Gagliardi AR, Lemieux-Charles L, Brown AD, Sullivan T, Goel V. Barriers to patient involvement in health service planning and evaluation: an exploratory study. Patient Educ Couns. 2008;70(2):234-241.

9. Fudge N, Wolfe CD, McKevitt C. Assessing the promise of user involvement in health service development: ethnographic study. $B M J$ 2008;336(7639):313-317.

10. Milewa T. User participation in service planning. A qualitative approach to gauging the impact of managerial attitudes. J Manag Med. 1997;11(4):238-245.

11. Rise MB, Grimstad H, Solbjør M, Steinsbekk A. Effect of an institutional development plan for user participation on professionals'knowledge, practice, and attitudes. A controlled study. BMC Health Serv Res. 2011;11:296.

12. Carr S. Participation, power, conflict and change: theorizing dynamics of service user participation in the social care system of England and Wales. Critical Social Policy. 2007;27(2):266-276. 
13. Daykin N, Sanidas M, Tritter J, Rimmer J, Evans S. Developing user involvement in a UK cancer network: professionals' and users' perspectives. Crit Public Health. 2004;14(3):277-294.

14. Jefford M, Tattersall MH. Informing and involving cancer patients in their own care. Lancet Oncol. 2002;3(10):629-637.

15. Wiener L, Zadeh S, Battles $\mathrm{H}$, et al. Allowing adolescents and young adults to plan their end-of-life care. Pediatrics. 2012;130(5): 897-905.

16. Thomas DM, Seymour JF, O'Brien T, Sawyer SM, Ashley DM. Adolescent and young adult cancer: a revolution in evolution? Intern Med J. 2006;36(5):302-307.

17. Thomas DM, Albritton KH, Ferrari A. Adolescent and young adult oncology: an emerging field. J Clin Oncol. 2010;28(32):4781-4782.

18. Bragazzi NL. Children, adolescents, and young adults participatory medicine: involving them in the health care process as a strategy for facing the infertility issue American Journal of Bioethics. $2013 ; 13(3) ; 43-44$

19. Treadgold CL, Kuperberg A. Been there, done that, wrote the blog: the choices and challenges of supporting adolescents and young adults with cancer. J Clin Oncol. 2010;28(32):4842-4849.

20. Pelusi J, Krebs LU. Understanding cancer-understanding the stories of life and living. J Cancer Educ. 2005;20(Suppl 1):12-16.

21. Iaconesi S. The cure [homepage on the Internet]. Available from: http:// artisopensource.net/cure/. Accessed April 3, 2013.

22. http://daily.wired.it/news/internet/2012/09/28/salvatore-iaconesiproposta-legge-ted-123234.html [homepage on the Internet]. Accessed April 3, 2013.

23. Buchanan A. Medical paternalism. Philos Public Aff. 1978;7(4): 370-390.

24. McKinstry B. Paternalism and the doctor-patient relationship in general practice. Br J Gen Pract. 1992;42(361):340-342.

25. Hood L, Friend SH. Predictive, personalized, preventive, participatory (P4) cancer medicine. Nat Rev Clin Oncol. 2011;8(3):184-187.

26. Gorini A, Pravettoni G. P5 medicine: a plus for a personalized approach to oncology. Nat Rev Clin Oncol. 2011;8(7):444.

27. Pravettoni G, Gorini A. A P5 cancer medicine approach: why personalized medicine cannot ignore psychology. J Eval Clin Pract. 2011;17(4): 594-596.

28. Ozdemir V, Knoppers BM. One size does not fit all: toward "upstream ethics"? Am J Bioeth. 2010;10(6):42-44.

29. McNutt RA. Shared medical decision making: problems, process, progress. JAMA. 2004;292(20):2516-2518.

30. Gurwitz D, Lunshof JE. Personalized participatory medicine: sharing knowledge and uncertainty. Genome Med. 2011;3(10):69.

31. Bottinger EP. Foundations, promises and uncertainties of personalized medicine. Mt Sinai J Med. 2007;74(1):15-21.

32. Ozdemir V, Faraj SA, Knoppers BM. Steering vaccinomics innovations with anticipatory governance and participatory foresight. OMICS. 2011;15(9):637-646.

33. Politi MC, Clark MA, Ombao H, Dizon D, Elwyn G. Communicating uncertainty can lead to less decision satisfaction: a necessary cost of involving patients in shared decision making? Health Expect. 2011; 14(1):84-91.

34. Haward MF, Lorenz JM. Communicating risk under conditions of uncertainty: not as simple as it may seem. Acta Paediatr. 2011;100(5): $651-652$.

35. Hamburg MA, Collins FS. The path to personalized medicine. $N$ Engl J Med. 2010;363(4):301-304.

36. Hutchinson L. Personalized cancer medicine: era of promise and progress. Nat Rev Clin Oncol. 2011;8(3):121.

37. Eisen MB, Spellman PT, Brown PO, Botstein D. Cluster analysis and display of genome-wide expression patterns. Proc Natl Acad Sci USA. 1998;95(25):14863-14868

38. Nicolini C, Bragazzi N, Pechkova E. Nanoproteomics enabling personalized nanomedicine. Adv Drug Deliv Rev. 2012;64(13):1522-1531.
39. Racapé M, Bragazzi N, Sivozhelezov V, et al. SMILE silencing and PMA activation gene networks in HeLa cells: comparison with kidney transplantation gene networks. J Cell Biochem. 2012;113(6): 1820-1832.

40. Bragazzi NL, Sivozhelezov V, Nicolini C. LeaderGene: a fast datamining tool for molecular genomics. J Proteomics Bioinform. 2011;4(4): 083-086.

41. Bragazzi NL, Pechkova E, Scudieri D, Terencio TB, Adami M, Nicolini C. Recombinant Laccase: II. Medical Biosensor. Crit Rev Eukaryot Gene Expr. 2012;22(3):197-203.

42. Brand A. Public Health Genomics and personalized healthcare: a pipeline from cell to society. Drug Metabol Drug Interact. 2012;27(3): 121-123.

43. Carrara S. Nano-bio-technology and sensing chips: new systems for detection in personalized therapies and cell biology. Sensors (Basel). 2010;10(1):526-543.

44. Chang HK, Ishikawa FN, Zhang R, et al. Rapid, label-free, electrical whole blood bioassay based on nanobiosensor systems. ACS Nano. 2011;5(12):9883-9891.

45. Zhang H, Tian M, Ignasi C, Cheng Z, Shen LH, Yang DJ. Molecular image-guided theranostic and personalized medicine. J Biomed Biotechnol. 2011;2011:673697.

46. Vidal M, Cusick ME, Barabási AL. Interactome networks and human disease. Cell. 2011;144(6):986-998.

47. Barabási AL, Gulbahce N, Loscalzo J. Network medicine: a networkbased approach to human disease. Nat Rev Genet. 2011;12(1):56-68.

48. Barabási AL. Network science: Luck or reason. Nature. 2012; 489(7417):507-508.

49. Sackett DL, Rosenberg WM, Gray JA, Haynes RB, Richardson WS. Evidence based medicine: what it is and what it isn't. BMJ. 1996; 312(7023):71-72.

50. Chen R, Mias GI, Li-Pook-Than J, et al. Personal omics profiling reveals dynamic molecular and medical phenotypes. Cell. 2012;148(6): 1293-1307.

51. Bensing J. Bridging the gap. The separate worlds of evidence-based medicine and patient-centered medicine. Patient Educ Couns. 2000; 39(1):17-25.

52. Bengoechea JA. Infection systems biology: from reactive to proactive (P4) medicine. Int Microbiol. 2012;15(2):55-60.

53. World Health Organization. [webpage on the Internet]. WHO definition of health. Available at http://www.who.int/about/definition/en/print. html. Accessed April 13, 2013.

54. Del Puente G, Bragazzi NL. The Bio-Psycho-Social Model: How accurate and valid is it? The bio-psycho-social model and beyond: its limitations and the need for a new model. A response to Eid's Editorial "The bio-psycho-social model: how accurate and valid is it?"

55. Bragazzi NL, Del Puente G. Why P6 medicine needs clinical psychology and a trans-cultural approach. Health Psychology Research. 2013;1(1):e5

56. Cumming G, Fowlie A, McKendrick D, et al. $\mathrm{H}=\mathrm{P} 4+\mathrm{C}$ and Health Web Science: "A Hippocratic Revolution in Medicine". Proceedings of the ACM WebSci '11 3rd International Conference on Web Science; June 14-17, 2010. Koblenz, Germany. Available from: http:// www.websci11.org/fileadmin/websci/Papers/Health_WS_WorkshopA_Hippocratic_Revolution.pdf. Accessed April 13, 2013.

57. Greenhalgh T, Hinder S, Stramer K, Bratan T, Russell J. Adoption, nonadoption, and abandonment of a personal electronic health record: case study of HealthSpace. BMJ. 2010;341:c5814.

58. Eysenbach G, Powell J, Englesakis M, Rizo C, Stern A. Health related virtual communities and electronic support groups: systematic review of the effects of online peer to peer interactions. $B M J$. 2004;328(7449):1166. 
Patient Preference and Adherence

Dovepress

\section{Publish your work in this journal}

Patient Preference and Adherence is an international, peer-reviewed, open access journal focusing on the growing importance of patient preference and adherence throughout the therapeutic continuum. Patient satisfaction, acceptability, quality of life, compliance, persistence and their role in developing new therapeutic modalities and compounds to optimize clinical outcomes for existing disease states are major areas of interest. This journal has been accepted for indexing on PubMed Central. The manuscript management system is completely online and includes a very quick and fair peer-review system. Visit http://www.dovepress.com/ testimonials.php to read real quotes from published authors.

Submit your manuscript here: http://www.dovepress.com/patient-preference-and-adherence-journal 